\title{
Refractory chronic migraine: a Consensus Statement on clinical definition from the European Headache Federation
}

\author{
Paolo Martelletti ${ }^{1,2^{*}}$, Zaza Katsarava ${ }^{3,4}$, Christian Lampl $^{5}$, Delphine Magis ${ }^{6}$, Lars Bendtsen ${ }^{7}$, Andrea Negro ${ }^{1}$, \\ Michael Bjørn Russell ${ }^{8,9}$, Dimos-Dimitrios D Mitsikostas ${ }^{10}$ and Rigmor Højland Jensen ${ }^{7}$
}

\begin{abstract}
The debate on the clinical definition of refractory Chronic Migraine (rCM) is still far to be concluded. The importance to create a clinical framing of these rCM patients resides in the complete disability they show, in the high risk of serious adverse events from acute and preventative drugs and in the uncontrolled application of therapeutic techniques not yet validated.

The European Headache Federation Expert Group on rCM presents hereby the updated definition criteria for this harmful subset of headache disorders. This attempt wants to be the first impulse towards the correct identification of these patients, the correct application of innovative therapeutic techniques and lastly aim to be acknowledged as clinical entity in the next definitive version of the International Classification of Headache Disorders 3 (ICHD-3 beta).
\end{abstract}

Keywords: Chronic migraine; Refractory chronic migraine; Disease progression; rCM classification

\section{Introduction}

Migraine is the most frequent neurological disease observed in clinical practice. This primary headache is associated with an important socioeconomic impact $[1,2]$ and the World Health Organization recognized the disorder as a major public health problem, by ranking it at 7th place among all worldwide diseases causing ictal disability $[3,4]$.

Migraine is a paroxysmal disorder with a natural fluctuation between a low and a high frequency pattern in part influenced by modifiable and non-modifiable risk factors [5]. Increased attack frequency can lead to the socalled 'chronic migraine' (CM), which then becomes less responsive to acute as well as prophylactic migraine medications [6].

The understandable need to treat all the migraine attacks combined with a reduced efficacy of rescue medications, can determinate the occurrence of medication overuse [7].

\footnotetext{
* Correspondence: paolo.martelletti@uniroma1.it

${ }^{1}$ Department of Clinical and Molecular Medicine, Sapienza University of Rome, Rome, Italy

${ }^{2}$ Regional Referral Headache Centre, Sant'Andrea Hospital, Rome, Italy

Full list of author information is available at the end of the article
}

All frequently used acute migraine medications, even when effective, seem to make the migraineurs brain more susceptible to migraine attack. In presence of $\mathrm{CM}$ and medication overuse, a vicious circle is built up, and the medication overuse becomes responsible of the persistence of the high frequency of the attacks (Medication Overuse Headache or $\mathrm{MOH}$ ) and lack of responsiveness to the abortive and to most preventive medications.

The treatment of choice for those patients is the withdrawal of the overused drug either performed at home, using some advice and patient coaching, or in hospital settings exclusively for patients who failed ambulatory detoxification or seem to have a real addictive behavior [8-11]. This two-steps approach, education first and then hospitalization, seems to be the more real and reliable if we look at the $1-2 \%$ gross prevalence of $\mathrm{MOH}$ in the total population [12].

The response to a preventive drug varies from person to person and fluctuates over time. Moreover comorbidities like depression, insomnia, anxiety, hypertension and obesity act as worsening factors in the chronification process [13]. 
Despite substantial advances in migraine therapy some individuals with migraine are refractory to guideline-based treatment [14]. Additionally recent studies revealed that the majority of migraine patients are undertreated in terms of use of prophylactic drugs [15], thus favouring the progression of migraine into chronicity.

In these past years the need to offer a rescue treatment and a better prevention to the so-called medically intractable chronic headache patients has raised the possibilities for neuromodulation and met the interest of device producers willing to lend support to this complex clinical situation.

\section{The concept of refractory chronic migraine}

The term CM is now well established in the clinical practice as well as in RCTs. The International Classification of Headache Disorders 3 beta (ICHD-3 beta) amended the main criteria of ICHD-2R for chronic migraine by adding the un-need to differentiate migraine with or without aura in the calculation of the monthly migraine days that must be 8 at least to the required criteria with a total of 15 headache days or more per month. Furthermore, the diagnosis can be ascertained even though a medication overuse exists, but in that case it is required that both $\mathrm{CM}$ and $\mathrm{MOH}$ diagnoses are added. The diagnosis of CM should then be revised after appropriate treatment of medication overuse as up to $3 / 4$ of CM patients reverts to an episodic form after detoxification $[8,10,11,16]$.

The term of refractory migraine has been used in the literature for a long time. In 1952 Reisman reported the first attempt to define refractory migraine by using a new experimental drug, namely ergot-alkaloids [17], but until recently, little attention has been paid to what it actually means to be refractory or how to define a patient as refractory.

Intractable migraine $[18,19]$ is another term that has been used interchangeably for the headache types we are addressing. If we go through the semantic of these terms, it is easy to realize that they describe two different conditions. While a refractory headache can improve or worsen over time also in relation to events independent of the headache, an intractable headache carries in itself the implication that the condition may never be improved.

In our opinion the term "refractory" - which is more frequently used in the literature - should be preferred because it better emphasizes the lack of treatment response. Although the term refractory migraine has been used in the literature for decades, operational criteria were not defined until recently.

Table 1 shows the first attempt to systematize this controversial issue. The proposal of intractable headache in migraine introduced the concept of failure of at least four classes of preventative drugs for the first time [20]. Two years later, in 2008, the Refractory Headache Special Interest Section (RHSIS) of the American Headache Society (AHS) proposed the criteria for both refractory episodic migraine and refractory chronic migraine (rCM) (Table 1) [21]. According to this definition, rCM must fulfill the ICHD-2R criteria for CM [22], and headaches have to cause significant interference with function or quality of life despite modification of triggers, lifestyle factors, and adequate trials of acute and preventive medicines with established efficacy. This definition requires that patients with migraine fail adequate trials of preventive drugs, alone or in combination, from at least 2 of 4 drug classes including: beta-blockers, anticonvulsants, tricyclics, and calcium channel blockers, whereas the term adequate is not further specified. Patients must also fail adequate trials of abortive medicines, including both a triptan and dihydroergotamine (DHE) intranasal or injectable formulation and either nonsteroidal anti-inflammatory drugs (NSAIDs) or combination analgesic, unless contraindicated. Since the RHSIS criteria, other proposed definitions included a rating scale to delineate the degree of intractability [23] and defined certain issues of treatment failure more precisely [24]. One aspect before considering a CM patient "refractory" to preventive therapy was the maximum possible number of drugs that had to be tested and found ineffective (Table 1) [25]. Likewise the beneficial use of multidisciplinary team in these difficult to treat patients is not further specified or requested despite guidelines recommendations.

Some authors may argue that it wouldn't be enough to try one medication of each pharmacological class (e.g., one beta-blocker, one anticonvulsants, etc.) as the members of a given class may work by various mechanisms and a patient unresponsive to one molecule may improve with another, and tolerability within a class varies too [25]. However, since the 2008 RHSIS proposal something has changed in the treatment scenario for chronic migraine patients. The results from the PREEMPT studies, published in 2010, have shown the efficacy and safety of onabotulinumtoxinA for the preventive treatment of CM [26] and it should also be added to the list of preventive therapy to try before labeling a migraine patient as refractory.

Despite the definitions provided by the current ICHD3 beta it does not include a definition of refractoriness in migraine [27]. A growing need of a shared definition of refractoriness has already been claimed from a multidisciplinary expert group [28].

It is not surprising that so far no consensus regarding the definition of rCM has emerged. It is still being debated what should be the key parameter of a definition of refractoriness (e.g., unresponsiveness to treatment, 
Table 1 Previous clinical definition of refractory chronic migraine

\begin{tabular}{|c|c|}
\hline Intractable headache (Goadsby (2006) & RHSIS criteria (AHS 2008) \\
\hline $\begin{array}{l}\text { Failed an adequate trial of regulatory } \\
\text { approved and conventional treatments } \\
\text { according to local national guidelines }\end{array}$ & A. ICHD-II migraine or chronic migraine \\
\hline $\begin{array}{l}\text { In migraine, failure of at least } 4 \text { classes, } \\
\text { where } 3 \text { should come from } 1 \text { to } 4\end{array}$ & $\begin{array}{l}\text { B. Headaches cause significant interference with } \\
\text { function or quality of life despite modification } \\
\text { of triggers, lifestyle factors, and adequate trials } \\
\text { of acute and preventive medicines with } \\
\text { established efficacy }\end{array}$ \\
\hline 1. Beta-blockers & $\begin{array}{l}\text { 1. Failed adequate trials of preventive medicines, } \\
\text { alone or in combination, from at least } \\
2 \text { of } 4 \text { drug classes: }\end{array}$ \\
\hline 2. Anticonvulsants & a. Beta blockers \\
\hline 3. Calcium channel blockers & b. Anticonvulsants \\
\hline 4. Tricylic antidepressants & c. Tricyclics \\
\hline 5. Other treatments with at least 1 & d. Calcium channel blockers \\
\hline
\end{tabular}

6. Nonsteroidal anti-inflammatory drugs

2. Failed adequate trials of abortive medicines from the following classes, unless contraindicated:

7. Metabolic enhancers, such as vitamin B2 • Both a triptan and DHE intranasal or or coenzyme Q10

injectable formulation

Adequate trial

Appropriate dose

- Either non-steroidal anti-inflammatory drugs or combination analgesics

Adequate trial

Appropriate length of time

Consideration of medication overuse

Period of time during which an appropriate dose of medicine is administered, typically at least 2 months at optimal or maximum-tolerated dose, unless terminated early due to adverse effects Modifiers

1. With or without medication overuse, as defined by ICHD-2

No therapeutic or unsatisfactory effect

2. With significant disability, as defined by MIDAS $\geq 11$
Refractory Migraine (after D'Amico 2008)

CM patients for whom adequate trials of preventive therapies at adequate doses have failed to reduce headache frequency and improve headache-related disability.

$\mathrm{MOH}$ patients should also be considered refractory when treatments fail to reduce the consumption of symptomatic drugs.

Preventive drugs

The greatest possible number of drugs should be tested and found ineffective (or intolerable).

It is not sufficient to try one medication of each pharmacological class.

Adequate trial

Adequate courses of all drugs considered as first-line prophylactics for episodic migraine by international guidelines, and in addition adequate courses of at least some of the drugs considered second- or third-line prophylactic treatments.

Trial duration and dosage

A 3-month treatment period is required to assess efficacy but it may be useful to continue for a further 3-6 months if there was some improvement during the first 3 months.

Treatment of medication overuse

Acute medication overuse should be curtailed before starting prophylaxis in patients with chronic headaches.

Treatment of comorbidities

Identification and appropriate treatment of all clinically significant comorbidities is essential before declaring a treatment failure in CM patients.

Intolerable side effects

Contraindications to use

high frequency, severe disability or all of these features) and if refractory headache should be considered as a single entity or rather a hard treatable version of different headache disorders [23].

Our opinion is that the definition of rCM should be based on the non-responsiveness to preventative treatment, not on the non-responsiveness to acute treatment. In fact the key for success is prevention: refractoriness is the consequence of prophylaxis failure while medication overuse headache can be both the cause and the consequence of the refractoriness itself. Therefore it is required that medication overuse headache should be 
ruled out or be adequately treated before a patient can be classified as refractory.

The attempt to define rCM has to keep in consideration what are meant to be the operational purposes of that classification as RCTs, referral from a primary care provider to a headache specialist, medical cost reimbursement, screening tool for invasive treatment or implantable devices. With the need of minimizing the risk of a misdiagnosis we have to exclude the possible causes of a false refractoriness and to focus on the small group of truly refractory patients.

A special attention should be paid to the very frequent presence of comorbidities (psychiatric and/or somatic) in this subset of rCM patients. Depression and anxiety disorders represent undisputable co-factors in the progression of migraine chronification and must be adequately treated [29-32].

Preventive medication should be preferably used as monotherapy, since our knowledge of combining different preventive medications is sparse. The combination topiramate and propranolol did not have any synergy effect and was not superior to either preventive medication given in monotherapy [33]. On the other hand, additional treatment of comorbidities is needed, either pharmacological or psychological, or even better a combination with a multidisciplinary team when available.

Using the criteria proposed by RHSIS $5.1 \%$ of the migraine patients evaluated in an US- headache clinic is diagnosed as refractory [21]. However until a well-accepted definition is formulated evidence-based treatment recommendations for $\mathrm{rCM}$ cannot be generated.

The clinical complexity of $\mathrm{rCM}$ moved the scientific interest to new concepts by studying interesting but still not sufficiently validated approaches, e.g. neuromodulation $[28,34]$.

The European Headache Federation (EHF) felt the need to develop new consensus criteria that define rCM, particularly for the purposes of controlled clinical trials that involve experimental medication and neuromodulation independently of the non-invasive therapies or the implantable devices.

Considering $\mathrm{rCM}$ as an evolution of $\mathrm{CM}$, we can hypothesize the inclusion of $\mathrm{rCM}$ as a 3-digit diagnosis of CM (1.3.1 Refractory chronic migraine) (see Table 2).

\section{Conclusions}

It is our opinion that exclusively headache experts should conduct the management of this migraine population particularly difficult to treat.

This EHF definition of rCM has to be considered as a mandatory tool in any multidisciplinary or innovative therapeutic approach.

The principal task of this EHF Expert Group Consensus Statement is to bring the definition of rCM up to date. For
Table 2 European Headache Federation proposed criteria for refractory chronic migraine

EHF proposed criteria for refractory chronic migraine

A. ICHD-III $\beta$ chronic migraine

No medication overuse

B. Prophylactic migraine medications in adequate dosages used for at least 3 months each.

C. Contraindications or No effect of the following preventive medication with at least 3 drugs from the following classes:

- Beta blockers

propranolol up to $240 \mathrm{mg} / \mathrm{d}$

metoprolol up to $200 \mathrm{mg}$

atenolol up to100mg

bisoprolol up to10mg

- Anticonvulsants

Valproate acid up to $1,5 \mathrm{~g} / \mathrm{d}$

Topiramate up to $200 \mathrm{mg} / \mathrm{d}$

- Tricyclics

amytriptyline up to $150 \mathrm{mg} / \mathrm{d}$

- Others

Flunarizine up to $10 \mathrm{mg} / \mathrm{d}$

Cardesartan $16 \mathrm{mg} / \mathrm{d}$

- OnabotulinumtoxinA

155 - $195 \mathrm{U}$ according to the PREEMPT protocol

D. Adequate treatment of psychiatric or other comorbidities by multidisciplinary team, if available.

Notes:

- Secondary Headache must be excluded

- MRI provides no underlying cause

- Laboratory and CSF analyses within normal range, including CSF pressure

- Meaning of efficacy: reduction on HA days $>50 \%$

- Detoxification procedure (in/out hospital setting): intravenous, oral and advice only are all accepted.

too long there has been a lot of utterance about it while their nosography was not systemized. So far few innovative neuromodulation practices have been widely applied to this subset of headaches, numerically limited but with a severe impact in terms of disability and social costs. Therapeutic results are before our eyes, still too scanty and often with weak scientific prerequisites. The lack of necessary evidence and its validation has made possible that, in the recent ICHD-3 $\beta$, refractoriness has found no room. It would be very valuable to scotomize this subset of headache patients with clear universal definitions instead of entrusting them only to striking case series without a scientific definition of refractoriness. This issue too must be investigated further in the course of the explorative work on refractoriness of headaches and its boundaries, by carefully field testings and using updated clinical criteria for rCM. 


\section{Competing interest}

PM received travel grants, consulting fees or unrestricted grants from Nevro Corporation, St Jude Medical, Allergan, Pfizer, ACRAF, is member of Advisory Board in Allergan and St Jude Medical as well as director in LTB and EHF. RHJ has given lectures for Pfizer, Berlin-Chemie, Allergan, Merck, ATI. Is also member of advisory boards in: ATI, Medotech, Neurocore, and Linde Gas as well as director in LTB, EHMTIC and President in EHF.

$\mathrm{CL}$ serves on scientific advisory boards for Allergan, Bayer HealthCare and St. Jude Medical; has received funding for travel from Bayer Schering Pharma, Pfizer, Allergan; served as a consultant to Bayer Schering Pharma, Biogen Idec; received research support from Bayer Schering Pharma, Allergan, Biogen Idec; has received personal compensation for consultations or lectures from Bayer HealthCare, Sanofi Aventis, Biogen Idec, Teva Pharmaceuticals, Pfizer.

DDM is member of advisory boards in Allergan, Astellas, Bayer-Schering, Novartis, Genzyme-Sanofi, Merck-Serono, Genesis Pharma, Teva, and has received honoraria for lecturing from Pfizer, Lilly, Menarini and UCB. DM has received travel grants from Allergan and research funds from Neurocore.

ZK, AN, DM and MBR declared no competing interests related to the contents of this Consensus Statement.

In details they had not received any research funds, travel or unrestricted grants, consulting fees, honoraria as speaker or consultant from the drug companies of the medicines or devices mentioned above.

Furthermore, all authors declare to not own any stock option of the manufacturers of drugs discussed in this review.

Finally, all the authors state they have received no direct or indirect payment in preparation of this manuscript.

\section{Authors' contributions}

All Authors on behalf of European Headache Federation contributed equally to the conception, design, drafting and critical revisions of the manuscript. The final version has been approved by all Authors.

\section{Acknowledgments}

This article, as a Consensus Article from experts in the topic, has been reviewed internally among Authors and the Editorial Office.

\section{Author details}

'Department of Clinical and Molecular Medicine, Sapienza University of Rome, Rome, Italy. ${ }^{2}$ Regional Referral Headache Centre, Sant'Andrea Hospital, Rome, Italy. ${ }^{3}$ Department of Neurology, Evangelical Hospital, Unna, Germany. ${ }^{4}$ Department of Neurology, University of Duisburg-Essen, Essen, Germany. ${ }^{5}$ Headache Center Seilerstaette, Department of Neurogeriatric medicine and Remobilisiation, Hospital Barmherzige Schwestern Linz, Linz, Austria. ${ }^{6}$ Department of Neurology, Headache Research Unit, University of Liège, Liège, Belgium. ${ }^{7}$ Danish Headache Center, Department of Neurology, University of Copenhagen, Glostrup Hospital, Copenhagen, Denmark. ${ }^{8} \mathrm{Head}$ and Neck Research Group, Research Center, Akershus University Hospital, Lørenskog, Norway. ${ }^{9}$ Institute of Clinical Medicine, Campus Akershus University Hospital, University of Oslo, Nordbyhagen, Norway. ${ }^{10}$ Department of Neurology, Naval Hospital, Athens, Greece.

\section{Received: 15 July 2014 Accepted: 29 July 2014}

Published: 28 August 2014

\section{References}

1. Steiner TJ, Birbeck GL, Jensen R, Katsarava Z, Martelletti P, Stovner $\sqcup$ (2011) The Global Campaign, World Health Organization and Lifting The Burden: collaboration in action. J Headache Pain 12:273-274

2. Bloudek LM, Stokes M, Buse DC, Wilcox TK, Lipton RB, Goadsby PJ, Varon SF, Blumenfeld AM, Katsarava Z, Pascual J, Lanteri-Minet M, Cortelli P, Martelletti P (2012) Cost of healthcare for patients with migraine in five European countries: results fromthe International Burden of Migraine Study (IBMS). J Headache Pain 13:361-378

3. Vos T, Flaxman AD, Naghavi M, Lozano R, Michaud C, Ezzati M, Shibuya K, Salomon JA, Abdalla S, Aboyans V, Abraham J, Ackerman I, Aggarwal R, Ahn SY, Ali MK, Alvarado M, Anderson HR, Anderson LM, Andrews KG, Atkinson C, Baddour LM, Bahalim AN, Barker-Collo S, Barrero LH, Bartels DH, Basáñez MG, Baxter A, Bell ML, Benjamin EJ, Bennett D, et al (2012) Years lived with disability (YLDs) for 1160 sequelae of 289 diseases and injuries 1990-2010: a systematic analysis for the Global Burden of Disease Study 2010. Lancet 380:2163-2196

4. Steiner TJ, Stovner LJ, Birbeck GL (2013) Migraine: the seventh disabler. $J$ Headache Pain 14(1):1

5. Negro A, D'Alonzo L, Martelletti P (2010) Chronic migraine: comorbidities, risk factors, and rehabilitation. Intern Emerg Med 5:S13-S19

6. Negro A, Rocchietti-March M, Fiorillo M, Martelletti P (2011) Chronic Migraine: current concepts and ongoing treatments. Eur Rev Med Pharmacol Sci 15:1401-1420

7. Negro A, Martelletti P (2011) Chronic migraine plus medication overuse headache: two entities or not? J Headache Pain 12:593-601

8. Tassorelli C, Jensen R, Allena M, De Icco R, Sances G, Katsarava Z, Lainez M, Leston J, Fadic R, Spadafora S, Pagani M, Nappi G (2014) The COMOESTAS Consortium. A consensus protocol for the management of medication-overuse headache: Evaluation in a multicentric, multinational study. Cephalalgia 34:645-655

9. Grande RB, Aaseth K, Saltyte Benth J, Gulbrandsen P, Russell MB, Lundqvist C (2009) The Severity of Dependence Scale detects people with medication overuse: theAkershus study of chronic headache. J Neurol Neurosurg Psychiatry 80(7):784-789

10. Grande RB, Aaseth K, Benth JŠ, Lundqvist C, Russell MB (2011) Reduction in medication-overuse headache after short information. The Akershus study of chronic headache. Eur J Neurol 18(1):129-137

11. Munksgaard SB, Bendtsen L, Jensen RH (2012) Treatment-Resistant Medication Overuse Headache Can Be Cured. Headache 52(7):1120-1129

12. Westergaard ML, Hansen EH, Glümer C, Olesen J, Jensen RH (2014) Definitions of medication-overuse headache in population-based studies and their implications on prevalence estimates: A systematic review. Cephalalgia 34:409-25

13. Bigal ME, Kurth T, Santanello N, Buse D, Golden W, Robbins M, Lipton RB (2010) Migraine and cardiovascular disease. A population-based study. Neurology 74:628-635

14. Lionetto L, Negro A, Palmisani S, Gentile G, Del Fiore MR, Mercieri M, Simmaco M, Smith T, Al-Kaisy A, Arcioni R, Martelletti P (2012) Emerging treatment for chronic migraine and refractory chronic migraine. Expert Opin Emerg Drugs 17:393-406

15. Kristoffersen ES, Grande RB, Aaseth K, Lundqvist C, Russell MB (2012) Management of primary chronic headache in the general population: the Akershus study of chronic headache. J Headache Pain 13:113-120

16. Zeeberg P, Olesen J, Jensen RH (2006) Discontinuation of medication overuse in headache patients: recovery of therapeutic responsiveness. Cephalalgia 26:1192-1198

17. Reisman EE Jr (1952) The use of experimental suppositories in treating refractory migraine. Am Pract Dig Treat 3(4):308-310

18. Goadsby PJ (2007) Neurostimulation in primary headache syndromes. Expert Rev Neurother 7(12):1785-1789

19. Schwedt TJ (2008) Occipital nerve stimulation for medically intractable headache. Curr Pain Headache Rep 12(1):62-66

20. Goadsby PJ, Schoenen J, Ferrari MD, Silberstein SD, Dodick DW (2006) Towards a definition of intractable headache for use in clinical practice and trials. Cephalalgia 26:1168-1170

21. Schulman EA, Lake AE 3rd, Goadsby PJ, Peterlin BL, Siegel SE, Markley HG, Lipton RB (2008) Defining refractory migraine and refractory chronic migraine: proposed criteria from the Refractory Headache Special Interest Section of the American Headache Society. Headache 48:778-782

22. Headache Classification Committee of International Headache Society (IHS) (2006) New appendix criteria open for a broader concept of chronic migraine. Cephalalgia 26:742-746

23. Levin M (2008) Refractory headache: classification and nomenclature. Headache 48:783-790

24. Schulman EA, Lipton R, Peterlin BL, Levin M, Grosberg BM (2010) Commentary from the Refractory Headache Special Interest Section on defining the pharmacologically intractable headache for clinical trials and clinical practice. Headache 50:1637-1639

25. D'Amico D, Leone M, Grazzi L, Bussone G (2008) When should "chronic migraine" patients be considered "refractory" to pharmacological prophylaxis? Neurol Sci 29:S55-S58

26. Dodick DW, Turkel CC, DeGryse RE, Aurora SK, Silberstein SD, Lipton RB, Diener HC, Brin MF (2010) PREEMPT Chronic Migraine Study Group. OnabotulinumtoxinA for treatment of chronic migraine: pooled results from the double-blind, randomized, placebo-controlled phases of the PREEMPT clinical program. Headache 50:921-936 
27. Headache Classification Committee of the International Headache Society (IHS) (2013) The International Classification of Headache Disorders, 3rd edition ( $\beta$ version). Cephalalgia 33:629-808

28. Martelletti $P$, Jensen $\mathrm{RH}$, Antal A, Arcioni R, Brighina F, de Tommaso M, Franzini A, Fontaine D, Heiland M, Jürgens TP, Leone M, Magis D, Paemeleire K, Palmisani S, Paulus W, May A (2013) Neuromodulation of chronic headaches: position statement from the European Headache Federation. J Headache Pain 14:86

29. Mitsikostas DD, Thomas AM (1999) Comorbidity of headache and depressive disorders. Cephalalgia 19(4):211-217

30. Breslau N, Schultz LR, Stewart WF, Lipton RB, Lucia VC, Welch KM (2000) Headache and major depression: is the association specific to migraine? Neurology 54:308-313

31. Pompili M, Serafini G, Di Cosimo D, Dominici G, Innamorati M, Lester D, Forte A, Girardi N, De Filippis S, Tatarelli R, Martelletti P (2010) Psychiatric comorbidity and suicide risk in patients with chronic migraine. Neuropsychiatr Dis Treat 6:81-91

32. Delgianni Cl, Vikelis M, Mitsikostas DD (2012) Depression in headaches: chronification. Curr Opin Neurol 25(3):277-283

33. Silberstein SD, Holland S, Freitag F, Dodick DW, Argoff C, Ashman E, Quality Standards Subcommittee of the American Academy of Neurology and the American Headache Society (2012) Evidence-based guideline update: pharmacologic treatment for episodic migraine prevention in adults: report of the Quality Standards Subcommittee of the American Academy of Neurology and the American Headache Society. Neurology 78(17):1337-1345, Erratum in: Neurology. 2013 Feb 26;80(9):871

34. Palmisani S, Al-Kaisy A, Arcioni R, Smith T, Negro A, Lambru G, Bandikatla V, Carson E, Martelletti P (2013) A six-year retrospective review of occipital nerve stimulation practice - controversies and challenges of an emerging technique for treating refractory headache syndromes. J Headache Pain $14: 67$

doi:10.1186/1129-2377-15-47

Cite this article as: Martelletti et al:: Refractory chronic migraine: a Consensus Statement on clinical definition from the European

Headache Federation. The Journal of Headache and Pain 2014 15:47.

\section{Submit your manuscript to a SpringerOpen ${ }^{\circ}$ journal and benefit from:}

- Convenient online submission

- Rigorous peer review

- Immediate publication on acceptance

- Open access: articles freely available online

- High visibility within the field

- Retaining the copyright to your article

Submit your next manuscript at $\gg$ springeropen.com 